\title{
Signal transduction inhibitors in treatment of myelodysplastic syndromes
}

Lohith Bachegowda ${ }^{1,2}$, Oleg Gligich²,3, Ionnis Mantzaris ${ }^{1,2}$, Carolina Schinke ${ }^{1,2}$, Dale Wyville', Tatiana Carrillo1, Ira Braunschweig ${ }^{1}$, Ulrich Steidl ${ }^{2}$ and Amit Verma ${ }^{1,2,4^{*}}$

\begin{abstract}
Myelodysplastic syndromes (MDS) are a group of hematologic disorders characterized by ineffective hematopoiesis that results in reduced blood counts. Although MDS can transform into leukemia, most of the morbidity experienced by these patients is due to chronically low blood counts. Conventional cytotoxic agents used to treat MDS have yielded some encouraging results but are characterized by many adverse effects in the predominantly elderly patient population. Targeted interventions aimed at reversing the bone marrow failure and increasing the peripheral blood counts would be advantageous in this cohort of patients. Studies have demonstrated over-activated signaling of myelo-suppressive cytokines such as TGF- $\beta$, TNF- $a$ and Interferons in MDS hematopoietic stem cells. Targeting these signaling cascades could be potentially therapeutic in MDS. The p38 MAP kinase pathway, which is constitutively activated in MDS, is an example of cytokine stimulated kinase that promotes aberrant apoptosis of stem and progenitor cells in MDS. ARRY-614 and SCIO-469 are p38 MAPK inhibitors that have been used in clinical trials and have shown activity in a subset of MDS patients. TGF- $\beta$ signaling has been therapeutically targeted by small molecule inhibitor of the TGF- $\beta$ receptor kinase, LY-2157299, with encouraging preclinical results. Apart from TGF- $\beta$ receptor kinase inhibition, members of TGF- $\beta$ super family and BMP ligands have also been targeted by ligand trap compounds like Sotatercept (ACE-011) and ACE-536. The multikinase inhibitor, ON-01910.Na (Rigosertib) has demonstrated early signs of efficacy in reducing the percentage of leukemic blasts and is in advanced stages of clinical testing. Temsirolimus, Deforolimus and other mTOR inhibitors are being tested in clinical trials and have shown preclinical efficacy in CMML. EGF receptor inhibitors, Erlotinib and Gefitinib have shown efficacy in small trials that may be related to off target effects. Cell cycle regulator inhibitors such as Farnesyl transferase inhibitors (Tipifarnib, Lonafarnib) and MEK inhibitor (GSK1120212) have shown acceptable toxicity profiles in small studies and efforts are underway to select mutational subgroups of MDS and AML that may benefit from these inhibitors. Altogether, these studies show that targeting various signal transduction pathways that regulate hematopoiesis offers promising therapeutic potential in this disease. Future studies in combination with high resolution correlative studies will clarify the subgroup specific efficacies of these agents.
\end{abstract}

Keywords: Myelodysplastic syndrome, Signal transduction inhibitors, Cytokines, TGF- $\beta$, ALK, EGFR, FTI, GSTP 1-1, ON- 01910.Na, Mek, mTOR

\footnotetext{
* Correspondence: amit.verma@einstein.yu.edu

'Division of Oncology, Montefiore Medical Center, 110, E 210 Street, Bronx, NY 10467, USA

${ }^{2}$ Albert Einstein College of Medicine, 1300 Morris Park Ave, Bronx, NY 10467,

USA

Full list of author information is available at the end of the article
}

\section{Biomed Central}

(c) 2013 Bachegowda et al.; licensee BioMed Central Ltd. This is an Open Access article distributed under the terms of the Creative Commons Attribution License (http://creativecommons.org/licenses/by/2.0), which permits unrestricted use, distribution, and reproduction in any medium, provided the original work is properly cited. 


\section{Review}

\section{Introduction}

Myelodysplastic syndromes (MDS) encompass a spectrum of hematologic diseases characterized by ineffective hematopoiesis in the marrow that leads to refractory cytopenia. Based on the degree of cytopenia and malignant potential, MDS can be classified as low or high grade subtypes, using the International Prognostic Scoring System [1]. In low grade MDS, marrow hyper cellularity and peripheral cytopenia are commonly seen due to upregulated apoptosis in the progenitor stem cells. However decreased apoptosis is seen during transformation to higher risk MDS, which often manifests with an increase in myeloblasts [2]. Most patients present with low risk disease and experience morbidity due to anemia, neutropenia or thrombocytopenia. Strategies to raise blood counts are needed to alleviate morbidity in these patients. Despite numerous advances, better understanding of pathways regulating hematopoiesis is still lacking. Since cytokines are important in regulating differentiation of hematopoietic cells, targeting them appears to be a rational therapeutic strategy in MDS. Various studies suggest Tumor Necrosis factor $\alpha($ TNF $\alpha)$ [3], Transforming Growth Factor $\beta($ TGF $\beta)$ [4], Vascular endothelial Growth Factor (VEGF) [5], Activin receptor like kinase (ALK) [6], Interleukins(ILs) [7], and Interferons (IFN) [8] regulate the bone marrow milieu in MDS. The physiologic effects of a few of these cytokines are executed by the support of transcription regulators like the JAKSTAT pathway and many other pathways [9]. Hence strategies that can balance the effects of the stimulatory and inhibitory cytokine pathways can potentially be of therapeutic utility in MDS and other hematologic neoplasm $[10,11]$.

\section{Cytokine regulation of hematopoiesis}

A complex interplay of various cytokines has been implied in maintaining normal hematopoiesis. Growth factors such as erythropoietin (EPO), Granulocyte macrophage colony stimulating factor (GM-CSF), Granulocyte colony stimulating factor (G-CSF) and Interleukin-3 promotes the differentiation of erythroid and myeloid progenitors [12]. On the other hand, Interferons, Interleukins, TGF- $\beta$ and TNF- $\alpha$ have inhibitory actions on hematopoietic stem cells (Figures 1 and 2). It is conceivable that an imbalance between the action of inhibitory and stimulatory cytokines can lead to increased myelo-suppression and bone

\section{STIMULATORY GROWTH FACTORS}

Erythropoietin (EPO), GCSF, GMCSF, TPO, IL-3, SCF

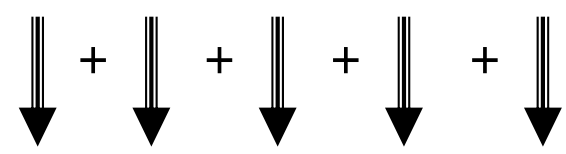

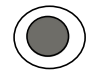

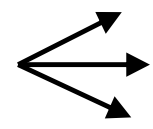

STEM CELL
HEMATOPOIESIS
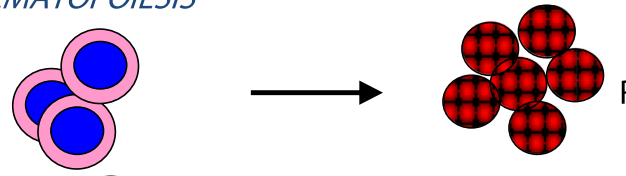

RED CELLS
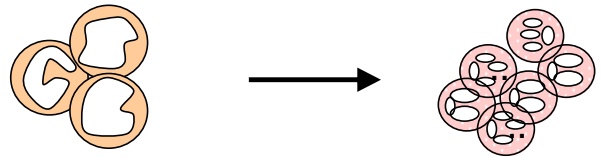

W.B.Cs
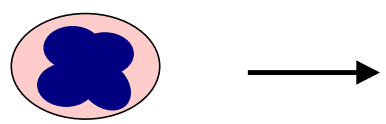

$\therefore \circ$ PLATELETS

PROGENITORS

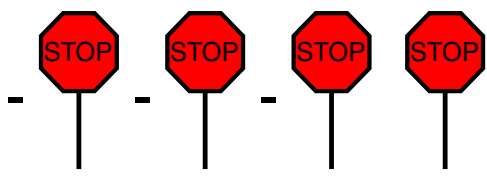

INHIBITORY CYTOKINES

Figure 1 Regulation of hematopoiesis by cytokines. The process of differentiation of hematopoietic stem cells into mature blood cells is tightly regulated by the actions of both stimulatory and inhibitory cytokines. 


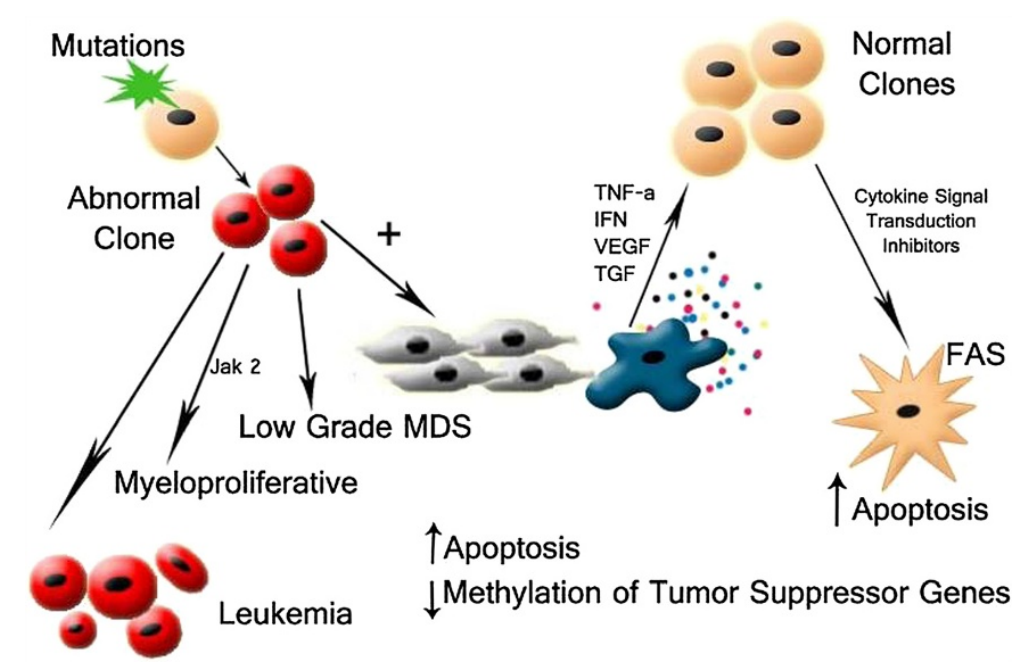

Figure 2 Model for pathogenesis of MDS. A mutation or epigenetic alteration in hematopoietic stem cells (HSC), leads to generation of pro-inflammatory milieu in marrow microenvironment that can result in apoptotic cell death of normal HSCs. Inhibition of myelo-suppressive cytokine signaling cascades can stimulate hematopoietic activity in HSCs.

marrow failure. In fact, excessive signaling of inhibitory cytokines is seen in MDS, thus making these pathways a potential target for therapy.

\section{P38 Mitogen Activated Protein (MAP) Kinase - \\ Therapeutic target in MDS}

Various inhibitory cytokines can activate the p38 MAPK pathway in the hematopoietic progenitor cells (Figure 3). In prior studies we have shown that this pathway is constitutively activated in MDS [13-15]. Activation of p38 MAPK was seen in a large proportion of bone marrow cells of patients with low grade MDS, with a greater number of phospho-p38-positive staining cells and significantly higher intensity of immunohistochemical

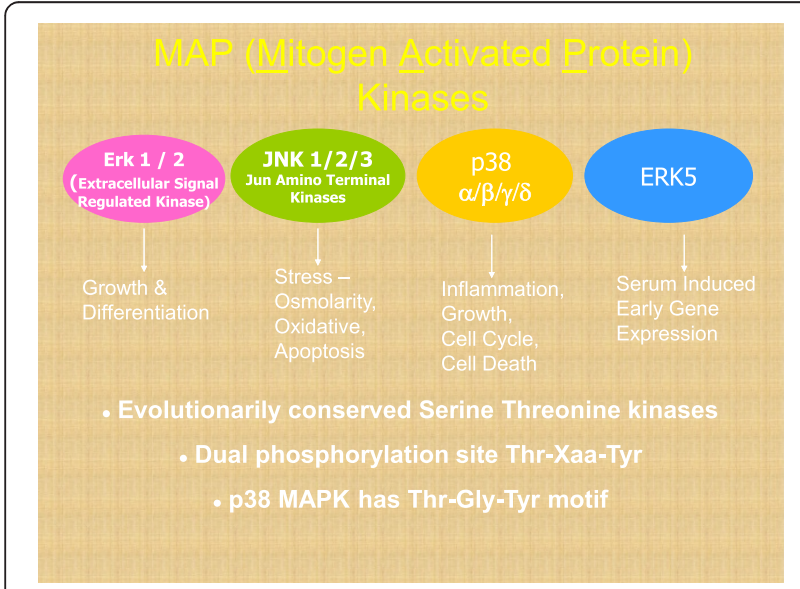

Figure 3 Mitogen activated protein kinases. These are evolutionarily conserved protein kinases that regulate many important physiological processes. The p38 MAP kinase regulates cell death and proliferation in hematopoietic cells. staining when compared to anemic non-MDS controls. We also determined that p38 MAPK activation mediates enhanced progenitor cell apoptosis seen in MDS bone marrows. Thus blocking this pathway is a potential therapeutic strategy that can lead to decrease in apoptosis and enhanced survival of hematopoietic stem and progenitor cells.

The compound SCIO-469, was the first small molecule inhibitor of the p38 MAPK that was tested clinically in MDS [16]. By predominantly inhibiting the alpha isoform (dominant isoform in MDS) of the P38 MAPK, this compound could stimulate hematopoiesis from MDS progenitors in vitro [17]. A phase $1 / 2$ multi center trial of SCIO- $469(\mathrm{~N}-62)$ was conducted in patients with low to intermediate risk MDS [18]. Patients in this trial received SCIO-469 at doses of $30 \mathrm{mg}$ TID (n-15), $60 \mathrm{mg}$ TID (n-15) and $90 \mathrm{mg}$ TID (n-15). Due to the fact that the maximum tolerable dose was not achieved, an additional arm with $120 \mathrm{mg}$ TID dosing (n-17) was added to the trial. Based on International Working Group criteria, responders were evaluated with an intention to continue using the drug until a maximum of 104 weeks of therapy. Of the 62 patients enrolled in the study only 47 of them completed the treatment till week 16. Only 12 of these patients were able to continue therapy after week 16 and 5 of them completed treatment till week 52. About $29 \%$ of patients ( 18 out of 62 ) experienced HI in each of the hematopoietic lineage. Amongst 62 study recruited patients, erythroid (6 major, 5 minor), neutrophil (3 major, 3 minor) and platelets (1 major) response were documented. Five patients were found to have progression of disease, 36 patients had stable disease and 1 patient achieved a cytogenetic response. Hence it was 
concluded that SCIO- 469 was found to be modestly active as a monotherapy in low- int risk MDS and recommended further studies at higher doses.

More recently, another p38 MAPK inhibitor, ARRY-614, has shown promising activity in MDS. This compound can block both the p38 MAPK and the Tie-2 pathway. Tie-2 pathway has been noted to complement P38 MAP kinase pathway in cytokine regulation and phenotypic maturation of hematopoietic stem cells [19]. Tie-2 ligands have been found to be over-expressed in marrows of MDS patients and higher expression of Tie- 2 has been correlated as a poor prognostic indicator [20]. A phase I trial of Arry-614 in low (n-11)/int-1(n-34) risk, heavily pretreated cohort of MDS patients was conducted recently [21]. In the inclusion criterion, prior therapies with erythropoietin stimulating agents (49\%), hypo-methylating agents (82\%) and lenalidomide (40\%) were permitted. ARRY- 614 at doses of 400-1200 mg once daily and 200-300 mg twice daily was administered in fasting state patients and a dose of $400 \mathrm{mg}$ daily was tested in non- fasting state. Of the 43 evaluable patients, hematological improvement was noted in 8 patients (erythroid-4, platelet-4 and neutrophil-5). Interestingly 5 bilineage improvement in counts was reported. Also the study demonstrated that ARRY-614 decreased the baseline elevated EPO levels and reduced platelet transfusions in patients who had failed therapy with hypomethylating agents. Hence it was hypothesized by the authors that addition of recombinant EPO in combination with ARRY- 614 may further optimize erythroid responses. Correlative studies showed that treatment with ARRY-614 resulted in an 85\% reduction of phosphorylated/activated-p38 levels in the marrow along with concomitant decreased apoptosis [22]. Based on encouraging responses, particularly in patients that failed hypomethylating agents, further clinical studies are being planned with this drug.

\section{Transforming Growth Factor- $\beta$ (TGF- $\beta$ ) inhibitors}

The role of TGF- $\beta$ cytokine on inhibition of normal stem and progenitor cells is well documented [23]. TGF- $\beta$ binds to a set of TGF- $\beta$ receptors and lead to activation of intracellular SMAD 2/3 proteins. These proteins associate with other cofactors and translocate to the nucleus to mediate the biological actions on stem cells. We have demonstrated that smad2, a downstream mediator of TGF- $\beta$ receptor I kinase (TBRI) activation, is constitutively activated and over expressed in MDS bone marrow precursors [24]. Furthermore, we showed that shRNA mediated down regulation as well as pharmacologic inhibition of TBRI leads to enhanced hematopoiesis in a variety of MDS subtypes in vitro. TBRI kinase inhibition also alleviated anemia and stimulated hematopoiesis in a mouse model of bone marrow failure, demonstrating it as a potential therapeutic target in MDS [4]. These studies provided a preclinical rationale for targeting TGF- $\beta$ signaling pathways in MDS.

LY2157299 is a novel small molecule that specifically inhibits the kinase activity of the Transforming Growth Factor- $\beta$ Type I Receptor (TGF- $\beta$ RI) and its downstream signaling pathway. In vitro and In vivo studies have shown the efficacy of LY2157299 in stimulating hematopoiesis in MDS [25], thus providing the rationale for using this drug in MDS (Figure 4). This agent is clinically relevant and has shown adequate safety signals in phase I studies in solid tumors [26]. This agent is also being tested clinically in gliomas and will be evaluated in MDS in the near future.

\section{Activin and TGF-beta receptor ligand traps}

The stimulatory role of erythropoietin (EPO) in erythropoiesis has been well established [27]. Hematopoietic cells in MDS are usually resistant to EPO and increased EPO level, reflecting a refractory state to therapy is often seen in the long course of this disease [28]. Consequently, only a minority of patients respond to recombinant EPO [29]. Activin family members belong to the TGF-superfamily ligands and plays important roles in cellular development of many different tissues including the hematopoietic tissue [30]. Hence compounds that can regulate Activin mediated hematopoietic activity have been tested for clinical applicability in MDS. ACE-536 is a modified type-II Activin receptor fusion protein and serves as a ligand trap for TGF- $\beta$ family members that are involved in erythroid differentiation. Preclinical trials in C57BL/6 mice were associated with rise in hematocrit, red blood cells and hemoglobin parameters at doses of $10 \mathrm{mg} / \mathrm{kg}$. The authors of this study observed a rapid proliferation of late stages of erythroid precursors, independent of EPO mediated mechanisms [31]. The encouraging stimulation of erythropoiesis observed led to further tests in the NUP98/HOX murine model of MDS [32]. When RAP-536 (The murine homolog of human ACE-536) was injected at $10 \mathrm{mg} / \mathrm{kg}$, twice a week for 8 months, it led to significant improvements in hematologic parameters in comparison to control studied. Authors reported that progression of anemia was much slower in mice treated with RAP-536 (8.3\% vs. $22 \%$ in HCT and $13 \%$ vs. $30 \%$ in RBC). Lack of increased blasts detected probably suggests a reduction in transformation to leukemia with RAP-536 treatment [33]. Currently a few phase-1/2 studies (Table one) are evaluating the role of ACE-536 in treating anemia.

Sotatercept (formerly known as ACE- 011) (fusion protein of Human soluble Activin receptor type-IIA and Fcportion of human IgG1) [34] is another ligand trap that has been shown to inhibit the inhibitory SMAD2/3 signaling in hematopoietic cells [35]. A recent clinical report of sotatercept in cancer patients and healthy volunteers has shown a rapid rise in hemoglobin and reticulocyte counts 


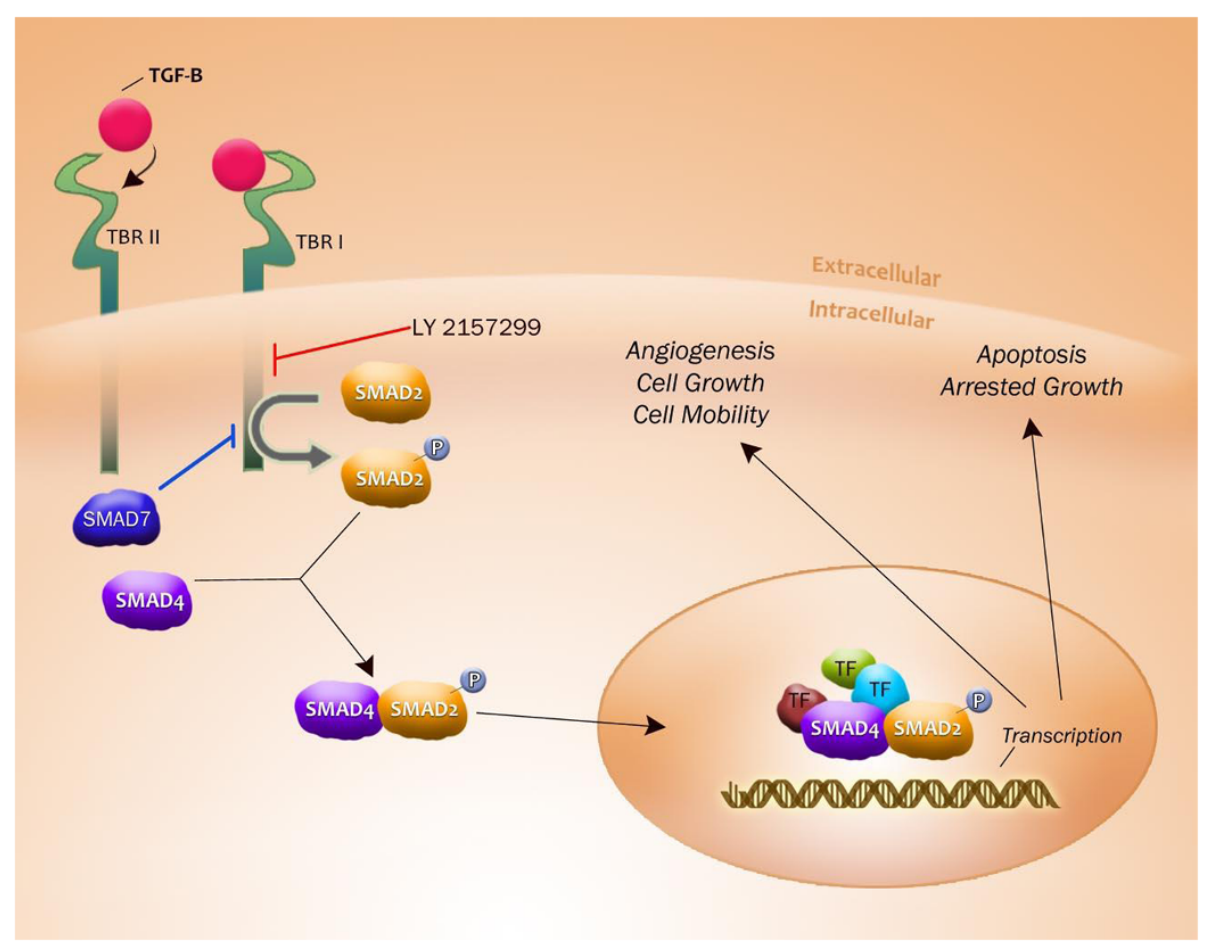

Figure 4 TGF- $\beta$ signaling pathway. TGF- $\beta$ receptors after binding with the TGF- $\beta$ ligand, forms a receptor- ligand complex. This dimerization activates the kinase domain of Type I receptor. The activated Type 1 receptor kinase further activates the downstream smad complexes to regulate gene transcription. LY2157299 inhibits the TGF- $\beta$ receptor I kinase and can reverse the cellular effects of TGF- $\beta$ signaling pathway in hematopoietic cells.

[36]. Various clinical trials (NCT01464164, NCT01571635 and NCT01736683) have been initiated and will explore the efficacy of this agent in treating anemia associated with marrow failure syndromes.

\section{Multi kinase inhibitor}

Onconova-01910.Na (Rigosertib) is a multi-kinase inhibitor of Polo like kinase, Akt and PI3 kinase pathways [37]. It appears to have selectivity for tumor cells containing these activated pathways and can cause apoptosis by inducing mitotic arrest at G2/M phase of cell cycle [38]. Preclinical studies in MDS demonstrated that ON-01910 could induce selective apoptosis in myeloid cells with trisomy of chromosome 8 . Trisomy 8 is a frequent cytogenetic alteration in MDS and is associated with upregulation of cyclin D1 and c-myc proteins, which drive cellular proliferation. Treatment of primary MDS samples containing trisomy 8 with $\mathrm{ON}-01910$ showed a reduction in CD34+ blasts in the first Phase 1 (NCT00533416) study conducted [39]. The trial included 12 patients with High risk MDS and 2 AML patients with trisomy-8. As reported in the study, 3 patients had greater than $50 \%$ reduction in blast counts \& 3 patients achieved hematologic improvement as per IWG criteria. All patients that showed a hematologic response to $\mathrm{ON}-01910$ had reduced expression of cyclin
D1 in CD34+ cells post therapy [39]. A more recent trial with Rigosertib in 60 MDS patients demonstrated the ability of this drug in reducing blasts and also revealed a positive correlation between bone marrow response and overall survival [40]. The encouraging results offered by this study have prompted an ongoing phase 3 study in MDS patients who have failed hypo-methylating agent therapy.

\section{Mammalian target of rapamycin inhibitors (mTOR inhibitors)}

The PI3K/mTOR pathway is an intracellular signaling pathway that is well studied in various cancers [41]. PI3K is a serine/threonine protein kinase that acts as a fulcrum and interface for various downstream pathways concerned with cell proliferation and metabolism [42,43]. By controlling enzymatic activity and decreasing angiogenesis, mTOR inhibitors have shown antiproliferative effects in various malignancies [44]. Preclinical studies have shown the oncogene, Ecotropic Viral Integration Site 1(EVI1) [45], a nuclear transcription factor is necessary for hematopoietic stem cell proliferation \& differentiation. In MDS and myeloid malignancies with EVI1 translocations, this transcription factor can cause PTEN repression and activation of PI3K/mTOR pathways [46], thereby leading to increased 
cell proliferation and reduced differentiation. Hence, many mTOR inhibitors are being studied as a novel strategy in treating MDS and other hematologic malignancies. Deforolimus has been studied in relapsed or refractory hematologic malignancies and has shown antitumor activity [47]. Temsirolimus is currently being evaluated in the TEMDS (Temsirolimus in MDS Study) trial (NCT 01111448). Unfortunately, NCT 00809185 which was meant to evaluate everolimus in MDS was terminated due to slow accrual. Despite this initial set back, with results of many studies yet to be presented, the role of mTOR inhibition could still hold promise in MDS [48].

\section{Epithelial Growth Factor Receptor (EGFR) inhibitors}

The arrival of EGFR inhibitors in clinical practice has significantly changed the landscape of lung cancer treatment in modern era and a similar attempt to replicate this success is tried in other cancers $[49,50]$. An interesting report of Gefitinib induced differentiation in AML cell lines and AML patient samples [51], spurred preclinical studies that reported pro apoptotic and anti-mitotic effects of erlotinib in EGFR negative MDS and AML cell lines [52]. This off target effect of EGFR inhibitor was attributed to blockage of Jak2/Stat-5 pathway in subsequent experiments [53]. A phase 2 study of erlotinib in MDS was reported at ASH 2010 [54]. In this study, patients who received Tarceva had failed prior Azacytadine or Decitabine. Amongst 23 reportable study patients who received $150 \mathrm{mg}$ Erlotinib tablets daily for 16 weeks, 3 went into CR, 1 showed hematologic improvement and 6 had stable disease. 4 patients died in the study arm. Diarrhea, platelet disorders and rash were commonly observed adverse events. Currently there is an ongoing NCT 1085838 clinical trial that is looking further into the role of erlotinib in High risk MDS. These studies have now been followed up by preclinical evaluation of combining erlotinib with azacytadine [55]. Another preclinical study reported that the combination of erlotinib with chemotherapeutic agents, leads to increased chemosensitivity in AML cell lines. This synergistic effect observed was achieved by promoting apoptosis and inhibiting the drug efflux from cells via inhibition of the $A B C$ transporters [56]. Based on these pre clinical studies further clinical studies are being designed to explore combinations of EGFR inhibitors with other agents.

\section{Ezatiostat (TLK199) (Glutathione S Transferase1-1 inhibitor)}

The enzyme GSTP1-1 (GSTP- Glutathione S Transferase pi1) can bind and inhibit the Jun Kinases with subsequent impact on growth and differentiation of healthy hematopoietic stem cells and cancer cells [57]. Ezatiostat is structurally analogous to Glutathione and can displace it from the glutathione binding site needed to inhibit the Jun
Kinase pathways. Hence Ezatiostat acts as a Glutathione S-Transferase P1-1 inhibitor and activates the pro apoptotic Jun kinase in cancer cells that express GSTP1-1[58]. This action promotes growth and maturation of normal hematopoietic progenitors and induces apoptosis in cancer cell lines. A recent phase 2 trial of Ezatiostat using 2 dosing schedules for heavily pretreated Low/Int-1 risk MDS (n-89) led to RBC transfusion reduction in 29\% and independence in $11 \%$ of transfusion dependent population [59]. Liposomal preparation of the compound showed encouraging results in one other Phase 2 MDS study [60]. The oral formulation of the compound is currently being studied in del5q MDS (NCT01422486). Since there are limited effective therapeutic options in non- del 5q MDS patients (low and intermediate-1 risk), Ezatiostat has been explored in combination with Lenalidomide in a phase-1 study. As per the design of this study patients received a starting dose of Lenalidomide $10 \mathrm{mg}$ for every 21 days followed by a week break in combination with 2 grams/day Ezatiostat. Dose escalation of Ezatiostat to 2.5 grams/day without changing the dose of Lenalidomide was carried out to determine the maximal tolerable dose and to determine the efficacy of combination therapy measured in terms of hematologic improvement. Amongst the 2.5 grams/day Ezatiostat with $10 \mathrm{mg}$ Lenalidomide receiving arm, about $25 \%$ of the patients experienced HI- E response. The HI- E response rate was $40 \%$ in 2 grams/day Ezatiostat arm and approximately $43 \%$ of patients who were red blood cell transfusion dependent prior to therapy become independent of transfusion post therapy. Also $60 \%$ of patients showed HI- P response. A significant proportion of bilineage (Erythroid/Platelet60\%) (Erythroid/Neutrophil and Neutrophil/Platelet-33\%) response was observed in $2000 \mathrm{mg}$ Ezatiostat arm. Interestingly, 33\% of patients had trilineage improvement with this combination. The combination was well tolerated and found a limited amount of gastrointestinal disturbance and low blood counts as commonly observed adverse events [61]. This study provides further impetus to test Ezatiostat in future phase 2 or 3 MDS studies, either as monotherapy or in combination with lenalidomide.

\section{Farnesyl Transferase Inhibitors (FTI)}

Farnesyl transferases regulate post translational farnesylation of protein substrates that are involved in cell signaling, proliferation and differentiation [62]. The oncogenic Ras protein requires post translational changes to become active in cancer cell lines with the help of the enzyme Farnesyl Transferase. Gain of function mutations in RAS are commonly seen with various cancers and this gene has been reported to be mutated in about approximately $20 \%$ of MDS patients [63]. Hence inhibitors of Farnesylation, that have shown antiangiogenic, antiproliferative and pro apoptotic 
functions in tumor cell lines [64-66] are being studied in MDS.

Tipifarnib (R115777) was studied in a phase 1 setting by Kurzrock et al. who tried doses of $300 \mathrm{mg}$ BID for 8 weeks schedule ( 3 weeks on and 1 week off). Of the 21 patients treated, only 4 of them had RAS mutation. Authors reported 30\% objective response with 3 patients showing HI, 2 showing PR and 1 reaching complete remission. Interestingly, amongst the responders only 2 of these 6 patients had a RAS mutation. The maximal tolerable dose as per this study was $400 \mathrm{mg}$ BID and myelo-suppression was a frequently reported side effect [67]. This was followed by a multicenter phase 2 study reported in 2004, where 28 patients received Tipifarnib. At doses of $600 \mathrm{mg}$ BID the compound was tested for 4 weeks followed by 2 weeks break. Treatment was discontinued at the end of 2 cycles if therapeutic effect was observed. A dose reduction to $300 \mathrm{mg}$ BID was allowed for toxicities. Once response was noted, patients were allowed to complete the induction regime for a total of 12 months. Three responders were observed in the trial (Complete-2, Partial-1). All responders had received an initial induction with R115777 of $600 \mathrm{mg}$ BID followed by dose reduction to 300 mg BID after 12 weeks. Low neutrophil count, weakness, gastrointestinal upset were often reported adverse events in the study [68]. A subsequent phase 2 study reported in 2007 tested R115777 in int- high risk MDS. In this study a total of 82 patients received the compound at doses of $300 \mathrm{mg}$ BID for 3 weeks followed by 1 week break from the compound. Of the 26 responders 12 had achieved CR, 14 had $\mathrm{HI}$ and about $45 \%(\mathrm{n}-37)$ were noted to be in stable disease. The median response duration amongst patients who had achieved CR was about 11.5 months. Approximately 18\% (neutropenia), (32\%) thrombocytopenia and (18\%) anemia was reported as drug related hematologic adverse events in this study [69].

Lonafarnib is another farnesyl transferase inhibitor that has been studied in MDS. In a phase 2 study, lonafarnib was studied in MDS and CMML patients (N-67) [70]. The drug was studied at doses of $200 \mathrm{mg}$ BID and $300 \mathrm{mg}$ BID. For patients who had greater than Grade 2 toxicity the dose was decreased to $150 \mathrm{mg}$ BID after interruptions. In this trial, HI was noted in 6 MDS patients and 10 CMML patients. Diarrhea, fatigue and nausea were the commonly reported adverse events with this compound. However earlier treatment withdrawal was noted amongst patients in the trial and the authors recommended intermittent dosing frequencies to be tested in future trials. Another phase 2 trial reported a very small benefit of lonafarnib in MDS at doses of $200 \mathrm{mg}$ BID for 3 courses of 4 weeks separated by 1-4 weeks of drug holiday [71]. With significant toxicity profile and modest benefit, lonafarnib needs to be further tested in large population studies and varied dosing schedule to find their clinical niche in MDS and AML.

\section{Mek inhibitor}

The binding of stimulatory growth factors can lead to the activation of Ras, Raf, MEK and ERK signaling cascades. These signaling cascades regulate proliferation, cell survival, angiogenesis and invasion [72]. Alteration in Mek/ Raf/Erk has been found to promote abnormal cell growth in Kras mediated MDS/myeloproliferative neoplasm (CMML/JMML) [73]. Constitutively activated MAP/Erk kinase pathways in various cancers with activating mutations in the RAS oncogene are often associated with poor prognosis [74,75]. Blocking Mek pathways in preclinical models of AML have resulted in growth inhibitory effects [76] and could potentially sensitize leukemic cells to chemotherapy induced apoptosis [77]. Mek kinase inhibitor, PD 0325901, has shown to improve erythropoiesis and rectify abnormal proliferation and differentiation pattern in mouse models of CMML and JMML [78]. A more recent study reported in ASCO 2011 demonstrated utility of MEK inhibition in relapsed/ refractory myeloid neoplasm. GSK1120212 (Mek- inhibitor) was given at $2 \mathrm{mg}$ daily dose to 45 patients with $\mathrm{K}$ or N RAS mutant MDS and led to an ORR of $31 \%$ and a CR rate of $23 \%$. Approximately $54 \%$ of these patients exhibited stable disease [79]. The utility of MEK inhibitors in suppressing mutant RAS mediated abnormal myeloproliferation and its ability to suppress apoptosis is currently being tested in clinical trials (Table 1).

Table 1 Relevant signal transduction inhibitors clinical trials in MDS

\begin{tabular}{lll}
\hline Family & Molecule & Trials \\
\hline P38 MAP kinase & SCIO-469, & NCT00113893 \\
inhibitors & ARRY-614 & NCT01496495 \\
$\begin{array}{l}\text { Activin and TGF- } \\
\beta \text { receptor ligand }\end{array}$ & ACE- 011 \& ACE & NCT 01736683 \\
trap & & NCT01432717 \\
$\begin{array}{l}\text { Multikinase } \\
\text { Inhibitor (PIk/Akt/ }\end{array}$ & Onconova-01910 & NCT00906334 \\
PI3) & & \\
P13K/mTOR & Deferolimus, & NCT00819546 NCT00086125 \\
inhibitors & Temsirolimus, & NCT00809185 NCT01111448 \\
& Everolimus, & \\
P13K/AKT & Perifosine & NCT00301938 \\
Inhibitors & & \\
EGF Receptor & Erlotinib & NCT01085838 NCT00977548 \\
Inhibitor & & \\
GSTPI-1 inhibitor & Ezatiostat & NCT00700206 NCT01422486 \\
Farnesyl & Tipifarnib, & NCT00005845 NCT00045396 \\
Transferase & Lonafarnib & NCT00050154 NCT00034684 \\
Inhibitors & & NCT00005967 \\
Mek Inhibitor & GSK1120212 & NCT00920140 \\
\hline
\end{tabular}




\section{TNF- a antagonist \\ Etanercept}

The efficacy of anti-TNF- $\alpha$ strategies in inflammatory conditions like rheumatoid arthritis [80] encouraged the testing of these agents in MDS. Increased levels of TNF- $\alpha$ have been reported in MDS marrows and this cytokine has been implicated in increased apoptosis noted with the disease [81]. TNF $\alpha$ inhibition was first tested in a phase 2 study by Deeg et al, in 12 MDS patients. Patients enrolled in the study received Etanercept $25 \mathrm{mg}$ s/c twice weekly dose with a plan to increase it to three times a week if there was no improvement in the counts by 8 th week. The study showed Hematologic Improvement in 3 parameters (erythroid $=4$, neutrophils $=2$, platelets $=2$ ). Interestingly there was no correlation observed between the pretreatment TNF- $\alpha$ levels and hematologic response [82].

\section{Infliximab (Remicaide) (Chimeric TNF alpha antibody)}

Similar to Etanercept, Remicade has also been used in Rheumatoid arthritis (auto immune disorder) and tested in MDS. Infliximab was tried in 2 cohorts of low risk MDS with 5 and $10 \mathrm{mg} / \mathrm{kg}$ doses respectively. The drug was designed to be given every 4 weeks for a total of 4 cycles. A total of 28 patients completed 4 cycles of which 8 patients showed hematologic response while 6 patients were found to have stable disease [83]. This was followed by a randomized Phase- 2 trial of Remicade in low risk MDS patients (EORTC 06023). In this study, the therapeutic efficacy of Infliximab at doses of $3 \mathrm{mg} / \mathrm{k}$ and $5 \mathrm{mg} / \mathrm{kg}$ was evaluated. A low response rate was noted with both the doses ( $3 / 22$ versus $0 / 21$ responses). Hence the study authors concluded that TNF- $\alpha$ blockade alone might be an insufficient therapeutic strategy in MDS.

\section{Conclusion}

Significant progress has been made in understanding the role of various cytokine cascades in MDS. Difficulties in stimulating normal marrow activity by conventional drugs alone provide opportunity to explore newer compounds that can alter and regulate ineffective hematopoiesis in MDS marrows. Currently P38 MAPK inhibitors, mTOR inhibitors, TGF- $\beta$ pathway inhibitors, MEK inhibitors and a few other compounds are being tested in various stages of clinical development. Finding an appropriate combination of novel agents and dosing frequencies that will enhance hematologic recovery would remain a challenge that needs to be addressed in newer studies. Future studies will be aided by correlative studies of Gene mutations, aberrant DNA cytosine methylation and other genetic/ epi- genetic biomarkers that will help identify a subset of MDS patients who might respond well to these new agents.

\section{Abbreviations}

MDS: Myelodysplastic syndrome; AML: Acute myeloid leukemia; IPSS: International prognostic scoring system; IWG: International working group; TID: Three times a day; HI: Hematologic Improvement: HI- E: Hematologic improvement- erythroid; HI- P: Hematologic improvement- platelet; HI- N: Hematologic improvement- neutrophil; CML: Chronic myelo monocytic leukemia; JMML: Juvenile myelo monocytic leukemia; IgG: Immunoglobulin G; TGF- $\beta$ : Transforming growth factor- $\beta$; MAPK: Mitogen activated protein kinase; MTOR: Mammalian target of rapamycin; ALK: Activin like kinase; EGFR: Epithelial growth factor receptor; GSTP 1-1: Glutathione S transferase pi1; TNF: Tumor necrosis factor; ON-01910 (Rigosertib): Multi kinase inhibitor; ACE- 011: Sotatercept; GSK: Glaxosmithkline; EPO: Erythropoietin; EORTC: European organization for research \& treatment of cancer; GM-CSF: Granulocyte macrophage colony stimulating factor; G-CSF: Granulocyte colony stimulating factor; shRNA: Small hair pin ribo nucleic acid.

\section{Competing interests}

The authors declare that they have no competing interest.

\section{Authors' contributions}

LB - Was responsible for reviewing literature, write up of Manuscript and proof- reading, OG- Responsible for Figures and proof reading, AV- Designed the review, expert opinion \& proof reading, Others- Corroborate with literature, proof reading and editorial responsibilities. All authors read and approved the final manuscript.

\section{Author details}

'Division of Oncology, Montefiore Medical Center, 110, E 210 Street, Bronx, NY 10467, USA. ${ }^{2}$ Albert Einstein College of Medicine, 1300 Morris Park Ave, Bronx, NY 10467, USA. ${ }^{3}$ Jacobi Medical Center, 1400 Pelham Pkwy S, New York, NY 10461, USA. ${ }^{4}$ Medicine/Oncology, Developmental \& Molecular Biology, 1300 Morris Park Ave, Bronx, NY 10461, USA

Received: 30 April 2013 Accepted: 29 May 2013

Published: 10 July 2013

\section{References}

1. Greenberg PL, Tuechler H, Schanz J, Sanz G, Garcia-Manero G, Sole F, Bennett JM, Bowen D, Fenaux P, Dreyfus F, Kantarjian H, Kuendgen A, Levis A, Malcovati L, Cazzola M, Cermak J, Fonatsch C, Le Beau MM, Slovak ML, Krieger O, Luebbert M, Maciejewski J, Magalhaes SM, Miyazaki Y, Pfeilstocker M, Sekeres M, Sperr WR, Stauder R, Tauro S, Valent P, et al: Revised International Prognostic Scoring System (IPSS-R) for myelodysplastic syndromes

Blood 2012. doi:10.1182/blood-2012-03-420489.

2. Greenberg PL: Apoptosis and its role in the myelodysplastic syndromes: implications for disease natural history and treatment. Leuk Res 1998, 22:1123-1136.

3. Mundle SD, Reza S, Ali A, Mativi Y, Shetty V, Venugopal P, Gregory SA, Raza A: Correlation of tumor necrosis factor alpha (TNF alpha) with high Caspase 3-like activity in myelodysplastic syndromes. Cancer Lett 1999, 140:201-207.

4. Zhou L, Nguyen AN, Sohal D, Ying Ma J, Pahanish P, Gundabolu K, Hayman J, Chubak A, Mo Y, Bhagat TD, Das B, Kapoun AM, Navas TA, Parmar S, Kambhampati S, Pellagatti A, Braunchweig I, Zhang Y, Wickrema A, Medicherla S, Boultwood J, Platanias LC, Higgins LS, List AF, Bitzer M, Verma A: Inhibition of the TGF-beta receptor I kinase promotes hematopoiesis in MDS. Blood 2008, 112:3434-3443. doi:10.1182/blood-2008-02-139824.

5. Savic A, Cemerikic-Martinovic V, Dovat S, Rajic N, Urosevic I, Sekulic B, Kvrgic V, Popovic S: Angiogenesis and survival in patients with myelodysplastic syndrome. Pathol Oncol Res 2012, 18:681-690.

6. Cunha SI, Pietras K: ALK1 as an emerging target for antiangiogenic therapy of cancer. Blood 2011, 117:6999-7006

7. Kordasti SY, Afzali B, Lim Z, Ingram W, Hayden J, Barber L, Matthews K, Chelliah R, Guinn B, Lombardi G, Farzaneh F, Mufti GJ: IL-17-producing CD4 (+) T cells, pro-inflammatory cytokines and apoptosis are increased in low risk myelodysplastic syndrome. Br J Haematol 2009, 145:64-72. doi:10.1111/j.1365-2141.2009.07593.x.

8. Sharma B, Altman JK, Goussetis DJ, Verma AK, Platanias LC: Protein kinase R as mediator of the effects of interferon (IFN) gamma and tumor necrosis 
factor (TNF) alpha on normal and dysplastic hematopoiesis. $J$ Biol Chem 2011, 286:27506-27514.

9. Furqan, et al: Dysregulation of JAK-STAT pathway in hematological malignancies and JAK inhibitors for clinical application. Biomarker Research 2013. doi:10.1186/2050-7771-1-2.

10. Greenberg P: Treatment of myelodysplastic syndrome with agents interfering with inhibitory cytokines. Ann Rheum Dis 2001, 60(Suppl 3):iii41-iii42.

11. Gupta D, Bachegowda L, Phadke G, Boren S, Johnson D, Misra M: Role of plasmapheresis in the management of myeloma kidney: a systematic review. Hemodial Int 2010, 14:355-363.

12. Newman K, Maness-Harris L, El-Hemaidi I, Akhtari M: Revisiting use of growth factors in myelodysplastic syndromes. Asian Pac J Cancer Prev 2012, 13:1081-1091.

13. Verma A, List AF: Cytokine targets in the treatment of myelodysplastic syndromes. Curr Hematol Rep 2005, 4:429-435.

14. Verma A, Deb DK, Sassano A, Kambhampati S, Wickrema A, Uddin S, Mohindru M, Van Besien K, Platanias LC: Cutting edge: activation of the p38 mitogen-activated protein kinase signaling pathway mediates cytokine-induced hemopoietic suppression in aplastic anemia. J Immunol 2002, 168:5984-5988.

15. Verma A, Deb DK, Sassano A, Uddin S, Varga J, Wickrema A, Platanias LC: Activation of the p38 mitogen-activated protein kinase mediates the suppressive effects of type I interferons and transforming growth factor-beta on normal hematopoiesis. J Biol Chem 2002, 277:7726-7735.

16. Schmierer B, Hill CS: TGFbeta-SMAD signal transduction: molecular specificity and functional flexibility. Nat Rev Mol Cell Biol 2007, 8:970-982.

17. Navas TA, Mohindru M, Estes M, Ma JY, Sokol L, Pahanish P, Parmar S, Haghnazari E, Zhou L, Collins R, Kerr I, Nguyen AN, Xu Y, Platanias LC, List AA, Higgins LS, Verma A: Inhibition of overactivated p38 MAPK can restore hematopoiesis in myelodysplastic syndrome progenitors. Blood 2006, 108:4170-4177. doi:10.1182/blood-2006-05-023093.

18. Sokol L, Cripe L, Kantarjian H, Sekeres MA, Parmar S, Greenberg P, Goldberg SL, Bhushan V, Shammo J, Hohl R, Verma A, Garcia-Manero G, Li YP, Lowe A, Zhu J, List AF: Randomized, dose-escalation study of the p38alpha MAPK inhibitor SCIO-469 in patients with myelodysplastic syndrome. Leukemia 2012. doi:10.1038/leu.2012.264.

19. Keith T, Araki Y, Ohyagi M, Hasegawa M, Yamamoto K, Kurata M, Nakagawa Y, Suzuki K, Kitagawa M: Regulation of angiogenesis in the bone marrow of myelodysplastic syndromes transforming to overt leukaemia. Br J Haematol 2007, 137:206-215. doi:10.1111/j.1365-2141.2007.06539.x.

20. Cheng CL, Hou HA, Jhuang JY, Lin CW, Chen CY, Tang JL, Chou WC, Tseng MH, Yao M, Huang SY, Ko BS, Hsu SC, Wu SJ, Tsay W, Chen YC, Tien HF: High bone marrow angiopoietin-1 expression is an independent poor prognostic factor for survival in patients with myelodysplastic syndromes. Br J Cancer 2011, 105:975-982. doi:10.1038/bjc.2011.340.

21. Komrokji RS, et al: Phase 1 Dose- escalation/expansion study of the P38/Tie 2 inhibitor ARRY- 614 in patients with IPSS low-int risk MDS; 2011. ASH Abstract 118. Presented on 12/11/2011, San Diego, California.

22. Winski SL, et al: Role of P38 MAPK and Tie 2 in the pathogenesis of MDS and their inhibition by dual inhibitor ARRY-614; 2012. ASH Abstract 2825. Presented on 12/09/2012 at Atlanta, Georgia.

23. Isufi I, Seetharam M, Zhou L, Sohal D, Opalinska J, Pahanish P, Verma A: Transforming growth factor-beta signaling in normal and malignant hematopoiesis. J Interferon Cytokine Res 2007, 27:543-552. doi:10.1089/jir.2007.0009

24. Bhagat TD, Zhou L, Sokol L, Kessel R, Caceres G, Gundabolu K, Tamari R, Gordon S, Mantzaris I, Jodlowski T, Yu Y, Jing X, Polineni R, Bhatia K, Pellagatti A, Boultwood J, Kambhampati S, Steidl U, Stein C, Ju W, Liu G, Kenny P, List A, Bitzer M, Verma A: miR-21 mediates hematopoietic suppression in MDS by activating TGF-beta signaling. Blood 2013, 121:2875-2881.

25. Zhou L, McMahon C, Bhagat T, Alencar C, Yu Y, Fazzari M, Sohal D, Heuck C, Gundabolu K, Ng C, Mo Y, Shen W, Wickrema A, Kong G, Friedman E, Sokol L, Mantzaris I, Pellagatti A, Boultwood J, Platanias LC, Steidl U, Yan L, Yingling JM, Lahn MM, List A, Bitzer M, Verma A: Reduced SMAD7 leads to overactivation of TGF-beta signaling in MDS that can be reversed by a specific inhibitor of TGF-beta receptor I kinase. Cancer Res 2011, 71:955-963
26. Ahnert $\mathrm{R}$, et al: First human dose (FHD) study of the oral transforming growth factor-beta receptor I kinase inhibitor LY2157299 in patients with treatment refractory malignant glioma. Clin Oncol 2011, 29:[suppl; abstr 3011]. Chicago: ASCO 2011.

27. Hedley BD, Allan AL, Xenocostas A: The role of erythropoietin and erythropoiesis-stimulating agents in tumor progression. Clin Cancer Res 2011, 17:6373-6380.

28. Sibon D, Cannas G, Baracco F, Prebet T, Vey N, Banos A, Besson C, Corm S, Blanc M, Slama B, Perrier H, Fenaux P, Wattel E, Groupe Francophone des M: Lenalidomide in lower-risk myelodysplastic syndromes with karyotypes other than deletion $5 q$ and refractory to erythropoiesis-stimulating agents. Br J Haematol 2012, 156:619-625. doi:10.1111/j.1365-2141.2011.08979.x.

29. Musto P, Falcone A, Sanpaolo G, Bodenizza C, La Sala A, Perla G Carella AM: Efficacy of a single, weekly dose of recombinant erythropoietin in myelodysplastic syndromes. Br J Haematol 2003, 122:269-271.

30. Wang Q, Huang Z, Xue H, Jin C, Ju XL, Han JD, Chen YG: MicroRNA miR-24 inhibits erythropoiesis by targeting activin type I receptor ALK4. Blood 2008, 111:588-595.

31. Suragani Rajashekar NVS, et al: ACE-536, A modified type ii activin receptor increases red blood cells in vivo by promoting maturation of late stage erythroblasts; 2010. ASH Abstract 4236; Presented on 12/06/2010 at Orlando, Florida.

32. Lin YW, Slape C, Zhang Z, Aplan PD: NUP98-HOXD13 transgenic mice develop a highly penetrant, severe myelodysplastic syndrome that progresses to acute leukemia. Blood 2005, 106:287-295.

33. Suragani RN: RAP-536 Promotes Terminal Erythroid Differentiation and Reduces Anemia in Myelodysplastic Syndromes; 2011. ASH Abstract 610; Presented at San Diego, California on 12/12/2011.

34. Lotinun S, Pearsall RS, Davies MV, Marvell TH, Monnell TE, Ucran J, Fajardo RJ, Kumar R, Underwood KW, Seehra J, Bouxsein ML, Baron R: A soluble activin receptor Type IIA fusion protein (ACE-011) increases bone mass via a dual anabolic-antiresorptive effect in Cynomolgus monkeys. Bone 2010, 46:1082-1088. doi:10.1016/j.bone.2010.01.370.

35. Raje N, Vallet $\mathrm{S}$ : Sotatercept, a soluble activin receptor type $2 \mathrm{~A}$ IgG-Fc fusion protein for the treatment of anemia and bone loss. Curr Opin Mol Ther 2010, 12:586-597.

36. Chen $\mathrm{N}$, et al: Exposures and Erythropoietic Responses to Sotatercept (ACE-011) in Healthy Volunteers and Cancer Patients: Implications for Mechanism of Action; 2012. ASH Abstract 3454; Presented at Atlanta on $12 / 10 / 2012$

37. Fan A, et al: A Novel Nano-Immunoassay (NIA) Reveals Inhibition of PI3K and MAPK Pathways in CD34+ Bone Marrow Cells of Patients with Myelodysplastic Syndrome (MDS) Treated with the Multi-Kinase Inhibitor On 01910.Na (Rigosertib); 2011. ASH Abstract 3808; Presented at San Diego, California on $12 / 12 / 2011$

38. Gumireddy K, Reddy MV, Cosenza SC, Boominathan R, Baker SJ, Papathi N, Jiang J, Holland J, Reddy EP: ON01910, a non-ATP-competitive small molecule inhibitor of Plk1, is a potent anticancer agent. Cancer Cell 2005, 7:275-286

39. Olnes MJ, Shenoy A, Weinstein B, Pfannes L, Loeliger K, Tucker Z, Tian X, Kwak M, Wilhelm F, Yong AS, Maric I, Maniar M, Scheinberg P, Groopman J, Young NS, Sloand EM: Directed therapy for patients with myelodysplastic syndromes (MDS) by suppression of cyclin D1 with ON 01910.Na. Leuk Res 2012, 36:982-989.

40. Raza A, et al: Final Phase I/II Results of Rigosertib (ON 01910.Na) Hematological Effects in Patients with Myelodysplastic Syndrome and Correlation with Overall Survival; 2011. ASH Abstract 3822, Presented at San Diego, Californiaon 12/12/2011

41. Alvarez M, Roman E, Santos ES, Raez LE: New targets for non-small-cell lung cancer therapy. Expert Rev Anticancer Ther 2007, 7:1423-1437.

42. Follo MY, Mongiorgi S, Bosi C, Cappellini A, Finelli C, Chiarini F, Papa V, Libra M, Martinelli G, Cocco L, Martelli AM: The Akt/mammalian target of rapamycin signal transduction pathway is activated in high-risk myelodysplastic syndromes and influences cell survival and proliferation. Cancer Res 2007, 67:4287-4294.

43. Chen BG, Guo QY, Zhang Y, Yan WH, Pan YQ, Zheng R, Li BL, Luo WD: Effect of rapamycin on apoptosis in human myelodysplastic syndrome cell line MUTZ-1 and its possible mechanisms. Zhongguo Shi Yan Xue Ye Xue Za Zhi 2010, 18:300-304. 
44. Frost $P$, Shi $Y$, Hoang $B$, Lichtenstein $A$ : AKT activity regulates the ability of mTOR inhibitors to prevent angiogenesis and VEGF expression in multiple myeloma cells. Oncogene 2007, 26:2255-2262.

45. Konrad TA, Karger A, Hackl H, Schwarzinger I, Herbacek I, Wieser R Inducible expression of EVI1 in human myeloid cells causes phenotypes consistent with its role in myelodysplastic syndromes. J Leukoc Biol 2009, 86:813-822

46. Yoshimi A, Goyama S, Watanabe-Okochi N, Yoshiki Y, Nannya Y, Nitta E, Arai S, Sato T, Shimabe M, Nakagawa M, Imai Y, Kitamura T, Kurokawa M: Evi1 represses PTEN expression and activates $\mathrm{PI} 3 \mathrm{~K} / \mathrm{AKT} / \mathrm{mTOR}$ via interactions with polycomb proteins. Blood 2011, 117:3617-3628.

47. Rizzieri DA, Feldman E, Dipersio JF, Gabrail N, Stock W, Strair R, Rivera VM, Albitar M, Bedrosian CL, Giles FJ: A phase 2 clinical trial of deforolimus (AP23573, MK-8669), a novel mammalian target of rapamycin inhibitor, in patients with relapsed or refractory hematologic malignancies. Clin Cancer Res 2008, 14:2756-2762.

48. Janakiram M, Thirukonda VK, Sullivan M, Petrich AM: Emerging Therapeutic Targets in Diffuse Large B-Cell Lymphoma. Curr Treat Options Oncol 2012. doi:10.1007/s11864-011-0178-9.

49. Xu C, Zhou Q, Wu YL: Can EGFR-TKls be used in first line treatment for advanced non-small cell lung cancer based on selection according to clinical factors? - A literature-based meta-analysis. J Hematol Onco/ 2012, 5:62.

50. Alexander C, Scot R, William T: EGFR inhibition in non-small cell lung cancer: current evidence and future directions. Bio Marker Research 2013. doi:10.1186/2050-7771-1-2

51. Stegmaier K, Corsello SM, Ross KN, Wong JS, Deangelo DJ, Golub TR: Gefitinib induces myeloid differentiation of acute myeloid leukemia. Blood 2005, 106:2841-2848.

52. Boehrer S: Increased Proliferation Induced by Constitutive Activation of the Src-Kinase Lyn and Aberrant mTOR Signaling in AML Is Abrogated by the EGFR-Inhibitor Erlotinib; 2009. ASH Abstract 3813;Presented at New Orleans on 12/07 2009.

53. Boehrer S, Ades L, Braun T, Galluzzi L, Grosjean J, Fabre C, Le Roux G, Gardin C, Martin A, de Botton S, Fenaux P, Kroemer G: Erlotinib exhibits antineoplastic off-target effects in AML and MDS: a preclinical study. Blood 2008, 111:2170-2180.

54. Komrokji RS, et al: Erlotinib for Treatment of Myelodysplastic Syndromes: A phase II clinical study; 2010. ASH Abstract 1854. Presented at Orlando, Florida on 12/4/2010

55. Lainey $\mathrm{E}$, et al: Potentiation of Apoptosis in MDS/AML by Combination of Azacitidine and the EGFR-Tyrosine Kinase Inhibitor (TKI) Erlotinib; 2011. ASH Abstract 2790. Presented at San Diego, California on 12/11/2011.

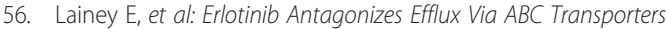
and Decreases P-Gp Cell Surface Expression by Inhibiting SRC Kinase and mTOR Pathways in Acute Myeloid Leukemia (AML); 2011. ASH Abstract 2564; Presented at San Diego on 12/11/2011.

57. Adler V, Yin Z, Fuchs SY, Benezra M, Rosario L, Tew KD, Pincus MR, Sardana M, Henderson CJ, Wolf CR, Davis RJ, Ronai Z: Regulation of JNK signaling by GSTp. EMBO J 1999, 18:1321-1334.

58. Galili N, Tamayo P, Botvinnik OB, Mesirov JP, Brooks MR, Brown G, Raza A: Prediction of response to therapy with ezatiostat in lower risk myelodysplastic syndrome. J Hematol Oncol 2012, 5:20.

59. Raza A, Galili N, Smith SE, Godwin J, Boccia RV, Myint H, Mahadevan D, Mulford D, Rarick M, Brown GL, Schaar D, Faderl S, Komrokji RS, List AF, Sekeres M: A phase 2 randomized multicenter study of 2 extended dosing schedules of oral ezatiostat in low to intermediate-1 risk myelodysplastic syndrome. Cancer 2012, 118:2138-2147.

60. Raza A, Galili N, Callander N, Ochoa L, Piro L, Emanuel P, Williams S, Burris H, Faderl S, Estrov Z, Curtin P, Larson RA, Keck JG, Jones M, Meng L, Brown GL: Phase 1-2a multicenter dose-escalation study of ezatiostat hydrochloride liposomes for injection (Telintra, TLK199), a novel glutathione analog prodrug in patients with myelodysplastic syndrome. J Hematol Oncol 2009, 2:20.

61. Raza A, Galili N, Mulford D, Smith SE, Brown GL, Steensma DP, Lyons RM, Boccia R, Sekeres MA, Garcia-Manero G, Mesa RA: Phase 1 dose-ranging study of ezatiostat hydrochloride in combination with lenalidomide in patients with non-deletion $(5 q)$ low to intermediate- 1 risk myelodysplastic syndrome (MDS). J Hematol Oncol 2012, 5:18.

62. Repasky GA, Chenette EJ, Der CJ: Renewing the conspiracy theory debate: does Raf function alone to mediate Ras oncogenesis? Trends Cell Biol 2004, 14:639-647. doi:10.1016/j.tcb.2004.09.014
63. Reuter CW, Morgan MA, Bergmann L: Targeting the Ras signaling pathway: a rational, mechanism-based treatment for hematologic malignancies? Blood 2000, 96:1655-1669.

64. Appels NM, Beijnen JH, Schellens JH: Development of farnesyl transferase inhibitors: a review. Oncologist 2005, 10:565-578.

65. Rowinsky EK, Windle JJ, Von Hoff DD: Ras protein farnesyltransferase: A strategic target for anticancer therapeutic development. J Clin Oncol 1999, 17:3631-3652.

66. End DW, Smets G, Todd AV, Applegate TL, Fuery CJ, Angibaud P, Venet M, Sanz G, Poignet H, Skrzat S, Devine A, Wouters W, Bowden C: Characterization of the antitumor effects of the selective farnesyl protein transferase inhibitor R115777 in vivo and in vitro. Cancer Res 2001, 61:131-137

67. Kurzrock R, Kantarjian HM, Cortes JE, Singhania N, Thomas DA, Wilson EF, Wright JJ, Freireich EJ, Talpaz M, Sebti SM: Farnesyltransferase inhibitor R115777 in myelodysplastic syndrome: clinical and biologic activities in the phase 1 setting. Blood 2003, 102:4527-4534.

68. Kurzrock R, Albitar M, Cortes JE, Estey EH, Faderl SH, Garcia-Manero G, Thomas DA, Giles FJ, Ryback ME, Thibault A, De Porre P, Kantarjian HM: Phase II study of R115777, a farnesyl transferase inhibitor, in myelodysplastic syndrome. J Clin Oncol 2004, 22:1287-1292.

69. Fenaux P, Raza A, Mufti GJ, Aul C, Germing U, Kantarjian H, Cripe L, Kerstens R, De Porre P, Kurzrock R: A multicenter phase 2 study of the farnesyltransferase inhibitor tipifarnib in intermediate- to high-risk myelodysplastic syndrome. Blood 2007, 109:4158-4163.

70. Feldman EJ, Cortes J, DeAngelo DJ, Holyoake T, Simonsson B, O'Brien SG, Reiffers J, Turner AR, Roboz GJ, Lipton JH, Maloisel F, Colombat $P$, Martinelli G, Nielsen JL, Petersdorf S, Guilhot F, Barker J, Kirschmeier P, Frank E, Statkevich P, Zhu Y, Loechner S, List A: On the use of lonafarnib in myelodysplastic syndrome and chronic myelomonocytic leukemia. Leukemia 2008, 22:1707-1711.

71. Ravoet C, Mineur P, Robin V, Debusscher L, Bosly A, Andre M, El Housni H, Soree A, Bron D, Martiat P: Farnesyl transferase inhibitor (lonafarnib) in patients with myelodysplastic syndrome or secondary acute myeloid leukaemia: a phase II study. Ann Hematol 2008, 87:881-885.

72. Messersmith WA, Hidalgo M, Carducci M, Eckhardt SG: Novel targets in solid tumors: MEK inhibitors. Clin Adv Hematol Oncol 2006, 4:831-836.

73. McCubrey JA, Steelman LS, Abrams SL, Bertrand FE, Ludwig DE, Basecke J, Libra M, Stivala F, Milella M, Tafuri A, Lunghi P, Bonati A, Martelli AM: Targeting survival cascades induced by activation of Ras/Raf/MEK/ERK, $\mathrm{PI3K} / \mathrm{PTEN} / \mathrm{Akt} / \mathrm{mTOR}$ and Jak/STAT pathways for effective leukemia therapy. Leukemia 2008, 22:708-722. doi:10.1038/leu.2008.27.

74. Sebolt-Leopold JS: MEK inhibitors: a therapeutic approach to targeting the Ras-MAP kinase pathway in tumors. Curr Pharm Des 2004, 10:1907-1914

75. Mueller H, Flury N, Eppenberger-Castori S, Kueng W, David F, Eppenberger U: Potential prognostic value of mitogen-activated protein kinase activity for disease-free survival of primary breast cancer patients. Int J Cancer 2000, 89:384-388.

76. Milella M, Kornblau SM, Estrov Z, Carter BZ, Lapillonne H, Harris D, Konopleva M, Zhao S, Estey E, Andreeff M: Therapeutic targeting of the MEK/MAPK signal transduction module in acute myeloid leukemia. J Clin Invest 2001, 108:851-859.

77. Milella M, Konopleva M, Precupanu CM, Tabe Y, Ricciardi MR, Gregorj C, Collins SJ, Carter BZ, D'Angelo C, Petrucci MT, Foa R, Cognetti F, Tafuri A Andreeff M: MEK blockade converts AML differentiating response to retinoids into extensive apoptosis. Blood 2007, 109:2121-2129.

78. Lyubynska N, Gorman MF, Lauchle JO, Hong WX, Akutagawa JK, Shannon K, Braun BS: A MEK inhibitor abrogates myeloproliferative disease in Kras mutant mice. Sci Trans/ Med 2011, 3:76ra27. doi:10.1126/scitranslmed.3001069.

79. Borthakur GLP, Kirschbaum MH, Foran JM, Kadia TM, Jabbour E, Boyiadzis M, Verma A, et al: Phase I/II trial of the MEK1/2 inhibitor GSK1120212 (GSK212) in patients (pts) with relapsed/refractory myeloid malignancies: Evidence of activity in pts with RAS mutation; 2011. ASCO abstract 6506, presented at ASCO 2011 meeting, Chicago.

80. Feldmann M, Maini RN: Anti-TNF alpha therapy of rheumatoid arthritis: what have we learned? Annu Rev Immunol 2001, 19:163-196. doi:10.1146/annurev.immunol.19.1.163.

81. Molnar L, Berki T, Hussain A, Nemeth P, Losonczy H: Detection of TNFalpha expression in the bone marrow and determination of TNFalpha production of peripheral blood mononuclear cells in myelodysplastic syndrome. Pathol Oncol Res 2000, 6:18-23. 
82. Deeg HJ, Gotlib J, Beckham C, Dugan K, Holmberg L, Schubert M, Appelbaum F, Greenberg P: Soluble TNF receptor fusion protein (etanercept) for the treatment of myelodysplastic syndrome: a pilot study. Leukemia 2002, 16:162-164. doi:10.1038/sj.leu.2402356.

83. Raza A, Candoni A, Khan U, Lisak L, Tahir S, Silvestri F, Billmeier J, Alvi MI, Mumtaz M, Gezer S, Venugopal P, Reddy P, Galili N: Remicade as TNF suppressor in patients with myelodysplastic syndromes. Leuk Lymphoma 2004, 45:2099-2104.

doi:10.1186/1756-8722-6-50

Cite this article as: Bachegowda et al: Signal transduction inhibitors in treatment of myelodysplastic syndromes. Journal of Hematology \&

Oncology 2013 6:50

\section{Submit your next manuscript to BioMed Central and take full advantage of:}

- Convenient online submission

- Thorough peer review

- No space constraints or color figure charges

- Immediate publication on acceptance

- Inclusion in PubMed, CAS, Scopus and Google Scholar

- Research which is freely available for redistribution 